\title{
Estimating Carbon Fractions of Plant and Soil Organic Materials from Ozonation Chemiluminescence
}

\author{
FAN Pingping ${ }^{\mathrm{a}}{ }^{*}, \mathrm{HOU}$ Guanglib and LIU Yan ${ }^{\mathrm{c}}$ \\ ${ }^{1}$ Full address of first author, including country \\ Key Laboratory of Shandong Provincial Ocean Environment Monitoring Technology, Institute of \\ Oceanographic Instrumentation, Shandong Academy of Sciences, Qingdao 266001, China \\ afanpp_sdioi@126.com, bhgl@sdioi.com, csdqdliuyan@126.com
}

\begin{abstract}
Keywords: Soil organic matter; Carbon (C) fractions; Ozonation; Chemiluminescence.
Abstract. The determination of $\mathrm{C}$ fractions in lab requires prior extraction steps that are laborious and time-consuming. Ozonation chemiluminescence can avoid the problem and has been successfully used to measure the $\mathrm{C}$ and $\mathrm{N}$ compounds in air or water, thus was proposed to determine $\mathrm{C}$ fractions of organic materials. Twenty-six different organic materials including soil organic matter and decomposed plant roots were examined. The changes of $\mathrm{C}$ fractions and molecular $\mathrm{C}$ structures for organic materials were studied during the ozonation process. Based on the ozonation process, three independent models were set up to predict $\mathrm{C}$ fractions by the luminescence characteristics. During ozonation all the three atoms of ozone were synthesized to the structure of new organic matter, thus the amount of carboxyl, carbonyl, or O-alkyl increased. C fractions can be assessed by the index of power function for luminescence intensity or luminescence time. Although some uncertainty exists in the models, this methodology provides a significant step forward from the traditional lab approach.
\end{abstract}

\section{Introduction}

Carbon (C) fractions of organic materials have been recognized to be the central control of decomposition process [1-3]. C fractions of organic materials include cellulose, hemicellulose, lignin, starch, protein, tannis, lipids, cutin, suberin, and other unknown substances [4]. Due to the tedious procedure during the determination, the dynamics of all $\mathrm{C}$ fractions are not studied; therefore, more details of litter decomposition have not shown.

Researchers have tried to study the rapid determination of $\mathrm{C}$ fractions in recent years. Vávrová et al. (2008) investigated several $\mathrm{C}$ fractions using near infrared reflectance spectroscopy (NIRS) including extractable substances, holocellulose, acid insoluble fractions, et al., and found a good r2 between predicted data and actual data (some $r^{2}$ up to 0.99) [5]. Artz et al. (2008) predicted C fractions using Fourier transform infrared (FTIR) spectra and found a good prediction for carbohydrates [6].

We found ozonation chemiluminescence has a potential to rapidly determine $\mathrm{C}$ fractions of organic materials [7-8]. Chemiluminescence is a light radiation produced in a chemical reaction process and the concentrations of substances can be determined based on the intensity or amount of light radiation [9]. Ozone has the strongest oxidation among the oxidants without pollution [10-12]; therefore, ozonation chemiluminescence has been widely used in environmental monitoring of air and water [13-14]. In air monitoring, NO concentrations are usually determined by ozonation chemiluminescence with a large detection range (>106) and a low detection limit (5 ng or 10-12). After an equivalent conversion with $\mathrm{NO}$, the concentrations of $\mathrm{N}$ compounds (such as nitrate) can be determined by ozonation chemiluminescence. Based on the mechanism, some products are commercialized, e.g., thermal analyzer [9]. In water monitoring, ozonation chemiluminescence is used to determine the total organic carbon and nitrogen compound [15-18].

Ozonation chemiluminescence is mainly applied in both gas phase reaction systems and liquid phase reaction systems, however, rarely in solid phase reaction systems. Hou et al. (2008) reported that ozonation chemiluminescence has the potential to determine the concentrations of soil organic matter [19]. After analyzing the luminescence characteristics and the concentrations of organic matter 
(Potassium dichromate reduction method) for 4 soil samples, a high relationship is found between luminescence characteristics and soil organic matter concentrations $\left(r^{2}=0.87\right)$. If the high relationship between luminescence characteristics and soil organic matter concentrations is general, soil organic matter concentrations can be examined from ozonation chemiluminescence in a short time $(<5 \mathrm{~min})$. The rapid determination has an advantage over the traditional method which is not only time consumed, but heavy polluted.

For the success of the rapid determination, more soil samples were studied. Results showed that the luminescence characteristics for some soils are different even if their organic matter concentrations are equal [7-8]. Liu et al. (2012a, b) explained that soil organic matter is highly heterogeneous and hypothesized that it is $\mathrm{C}$ fractions (not organic matter concentrations) that control luminescence characteristics [7-8]. And Liu et al. (2012a, b) found that difference of C fractions can explain the most variation of luminescence characteristics and that ozonation chemiluminescence has a potential to determine soil $\mathrm{C}$ fractions [7-8].

However, the method to examine $C$ fractions of organic materials is still not clear. In this study we will study the ozonation process, based on which explore the method to examine $\mathrm{C}$ fractions of organic materials from ozone chemiluminescence. Due to the limitation of detection technology, $\mathrm{C}$ fractions in decomposition studies are roughly classified as acid soluble fractions (AS), acid insoluble fractions (AIF), and extractives (Lip) in our study. AS are composed of variety of polysaccharide (e.g., cellulose and semicellulose), thus decompose the most rapidly with the fastest rate of nutrient release; AIF are composed of polyphenolics, lignin, suberin, and other acid insoluble substances, thus decompose slowly; Lip are composed of polar substances, such as lipids, which are difficult to be decomposed [1-2].

\section{Materials and Methods}

Sample collection and lab preparation. The 26 samples of natural organic matter examined in this study included soils and decomposed plant roots. The soils examined originated from 16 fields in 2009 [7-8] and 2 plantations in 2009 [3]. The field soils were collected from the $0-10 \mathrm{~cm}$ layer near Chaolian Island, Qingdao, Shandong Province (CI), Red Island, Qingdao, Shandong Province (RI), The 6th beach of Qingdao, Shandong Province (6B), Fushan, Qingdao, Shandong Province (FS), Laizhou, Shandong Province (LZ), Dongying, Shandong Province (DY), Heze, Shandong Province (HZ), Ji'ning, Shandong Province (JN), Tai' an, Shandong Province (TA), Qing'an, Heilongjiang Province (QA), Mudanjiang, Heilongjiang Province (DB), Hailaer, Neimeng Province (NM), Huaibei, Anhui Province (HB), Zhuhai, Guangdong Province (ZH), Guangzhou, Guangdong Province (GZ), Sanya, Hainan Province (SY). Of these soils, DY, FS, JN, and QA were studied in different dates, so they had different signs as DY', FS', JN', and QA'. The plantation soils were collected from the $0-10 \mathrm{~cm}$ layer in the Phellodendron amurense plantations (BS) and Picea aspirate plantations (YS). The plant roots examined were sampled from 0-20 cm layer in the Phellodendron amurense (signed as B) plantations and Picea aspirate (signed as Y) plantations of Maoershan, Heilongjiang Province. These roots were separated to first order (R1), second order (R2), third order (R3), fourth order (R4), and fifth order (R5) and decomposed for 2 years in litterbags. These decomposed roots are signed as B_R1, B_R2, B_R3, B_R5, Y_R2, Y_R4, and Y_R5. All samples were dried at $65^{\circ} \mathrm{C}$ for $48 \mathrm{hr}$ and ground to pass the $0.1 \mathrm{~mm}$ mesh for ozonation analysis and chemical analysis.

Ozonation analysis. Samples were oxidized by ozone $\left(\mathrm{O}_{3}\right)$ using an instrument developed for this study (named as OM-Ozonation_Hou) and their luminescence characteristics were analyzed by a related software (named as C-Plot) [19]. OM-Ozonation_Hou has an $\mathrm{O}_{3}$ generator, a reaction chamber, and a set of control systems related to C-Plot [7-8]. By C-Plot, the luminescence characteristics are expressed as a curve whose $\mathrm{x}$-axis is time (s) and $\mathrm{y}$-axis is luminescence intensity (voltage, mv). In this study, we added the $\mathrm{O}_{3}$ concentration meter and gas flowmeter in front of and behind the reaction chamber to measure the amount of $\mathrm{O}_{3}$ consumed during ozonation. Dried samples were weighed and flatly fixed in the reaction chamber, then started to be oxidized by $\mathrm{O}_{3}$. Luminescence 
signals and time were read as a curve by C-Plot. The luminescence signal goes to the maximum at short time $(<1 \mathrm{~s})$, then slows down as the power function. The basic parameters including the signal intensity (V), luminescence time (t), and integrated area of the curve (A) were also analyzed by C-Plot, which expressed the luminescence characteristics of samples with different $\mathrm{C}$ fractions.

Chemical analysis. $\mathrm{C}$ fractions of the original samples and the oxidized samples were measured following the method of Liu et al. (2012a, b) [7-8]. Briefly, samples were first extracted by a chloroform methanol mixture ( $\mathrm{v} / \mathrm{v}=2: 1)$. After $2 \mathrm{hr}$, filtered the solution and dried the residues at $110^{\circ} \mathrm{C}$ for $12 \mathrm{hr}$. Then, the dried residues were digested in sulfuric acid (72\%) for $3 \mathrm{hr}$. Filtered the solutions using hot water and dried the residues at $110^{\circ} \mathrm{C}$ for $12 \mathrm{hr}$. Lip are the fractions extracted by the chloroform methanol mixture, AS are the fractions digested in the sulfuric acid, and AIF are the residues digested by the sulfuric acid. The molecular $\mathrm{C}$ structures were analyzed by nuclear magnetic resonance (NMR). Spectra were acquired at a 13C frequency of $75.5 \mathrm{MHz}$ on a Bruker AV 300 spectrometer. The samples were packed into a $4 \mathrm{~mm}$ diameter cylindrical zirconia rotor with Kel-F end-caps and spun at $12000 \mathrm{~Hz}$ in a Doty Scientific MAS probe. A cross-polarisation AV pulse sequence was used to establish the optimum contact time and the contact time is $2 \mathrm{~ms}$. The chemical shift regions used in this study were $210-165 \mathrm{ppm}$ and $165-145 \mathrm{ppm}$, in which the former corresponds to the carboxyl $\mathrm{C}$ and carbonyl $\mathrm{C}$ and the latter corresponds to the O-aryl [20].

Data analysis. The basic luminescence characteristics were first analyzed. A power function of $\mathrm{V}$ was simulated by the points $(\mathrm{t} 100, \mathrm{~V}),(\mathrm{t} 75,0.75 \mathrm{~V}),(\mathrm{t} 50,0.5 \mathrm{~V}),(\mathrm{t} 33,1 / 3 \mathrm{~V}),(\mathrm{t} 16,1 / 6 \mathrm{~V})$, and $(\mathrm{t} 10$, $0.1 \mathrm{~V})$ and a power function of $\mathrm{A}$ was simulated by the points $(\mathrm{t} 100,0),(\mathrm{t} 75,0.75 \mathrm{~A}),(\mathrm{t} 50,0.5 \mathrm{~A}),(\mathrm{t} 33$, $1 / 3 \mathrm{~A}),(\mathrm{t} 16,1 / 6 \mathrm{~A})$, and $(\mathrm{t} 10, \mathrm{~A})$. In the functions, $\mathrm{t} 100$ is the time when the signal intensity is the maximum, $\mathrm{t} 75$ is the time consumed when the signal intensity was $75 \%$ of the maximum from $\mathrm{t} 100, \mathrm{t} 10$ is the time consumed when the signal intensity was $10 \%$ of the maximum from 100 , and so on $\mathrm{t} 75<\mathrm{t} 50<\mathrm{t} 33<\mathrm{t} 16<\mathrm{t} 10) ; 0.75 \mathrm{~A}$ is the integrated area from $\mathrm{t} 100$ to $\mathrm{t} 75$, $\mathrm{A}$ is the integrated area from $\mathrm{t} 100$ to $\mathrm{t} 10$, and so on $(0.75 \mathrm{~A}<0.5 \mathrm{~A}<1 / 3 \mathrm{~A}<1 / 6 \mathrm{~A}<\mathrm{A})$. Because the sample weight is highly correlated with their luminescence characteristics, all the luminescence characteristics were expressed as the unit of mg-1. General linear regression was conducted between the luminescence characteristics and C fractions. T-test was used to test the statistical significance of the regression. Statistical analyses were conducted using SPSS 17.0.

\section{Results and Discussions}

Ozonation Process. The whole ozonation process lasted for at most $6 \mathrm{~min}$. For most samples the ozonation process lasted for $5 \mathrm{~min}$, but for some samples (such as JN, GZ, SY) the ozonation process lasted for less than $1 \mathrm{~min}$ (data not shown). It is indeed a rapid determination for $\mathrm{C}$ fractions of organic materials.

After ozonation, the increased mass of samples is not smaller than the consumed amount of $\mathrm{O}_{3}(\mathrm{Fig}$. 1). Under the condition, all the three atoms of $\mathrm{O}_{3}$ were synthesized to the structure of new organic matter. Correspondence to the ozonation, NMR data showed that the amount of the carboxyl and carbonyl (210-165 ppm, Fig. 2a) or O-aryl (165-145 ppm, Fig. 2b) increased, confirming the addition of oxygen during the ozonation process. 


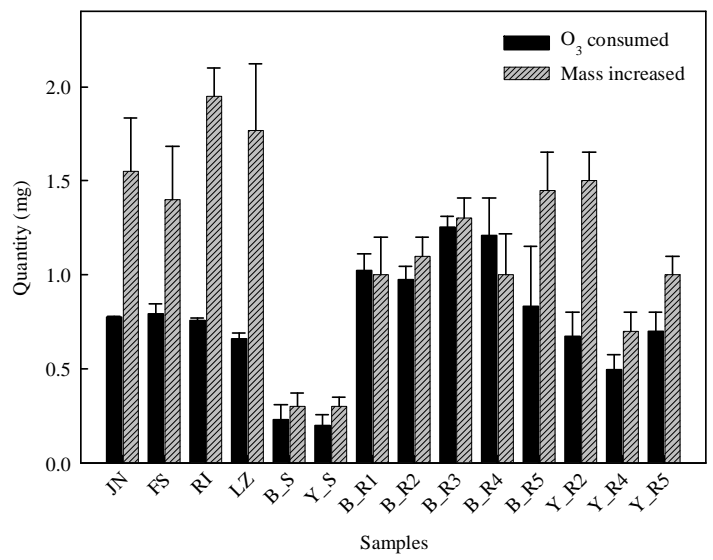

Fig. 1. Mass increased and ozone consumed for plant and soil samples after ozonation.

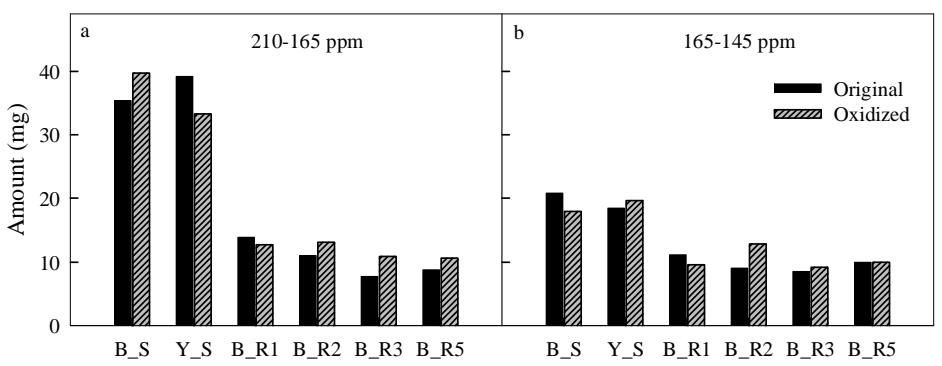

Fig. 2. Amount of NMR fractions for some plant and soil samples before and after ozonation.

Estimating $\mathbf{C}$ fractions from luminescence characteristics. Although ozonation is the process of $\mathrm{O}_{3}$ consumed and the amount of consumed $\mathrm{O}_{3}$ is highly related with the concentrations of $\mathrm{C}$ fractions, $\mathrm{r}^{2}$ is smaller than 0.65 (data not shown). Therefore, other models with high $\mathrm{r}^{2}$ were selected. Lip concentrations had been predicted by the index of power function for luminescence intensity and luminescence time ( $\mathrm{Lip} \%=-2.94-9370.8 \times(b-V) / m$, Fig. 3a) and AS and AIF concentrations had been predicted by the luminescence time $(A S \%=5.03+18.9 \times t / m, A \mathrm{I} F \%=95.85-29.5 \times t / m$, Fig. $3 b-c)$.
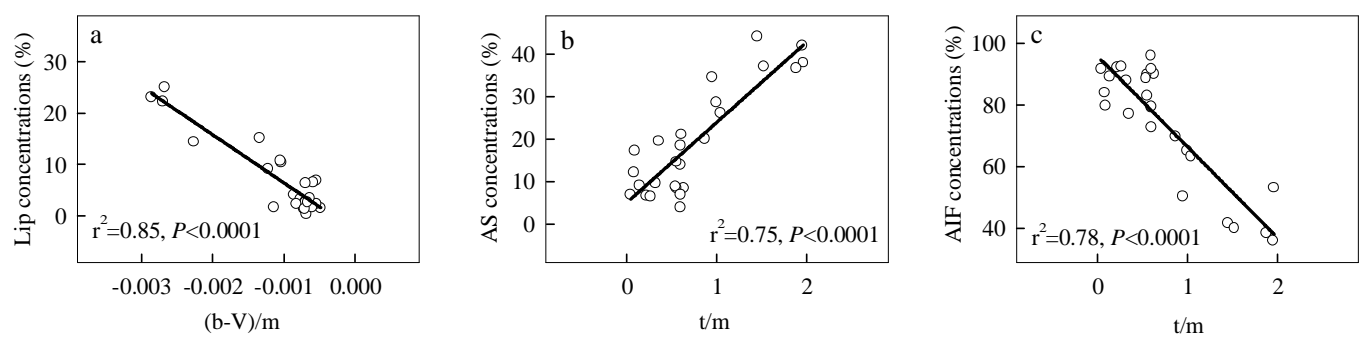

Fig. 3. Prediction models for $C$ fractions. Lip concentrations are predicted by the index of the power function for luminescence intensity and luminescence time (Fig.5a; (b-V)/m), AS concentrations and AIF concentrations are predicted by the luminescence time (Fig. $5 b, 5 c ; t / m)$.

Similar to these models, two models based on the relationship between $\mathrm{C}$ fractions and chemiluminescence characteristics were set up using some of soils in this study (Liu et al., 2012b) [8]. The chemiluminescence characteristics selected the index of power function for luminescence intensity and luminescence time, which is not standardized by sample mass; therefore, the models in Liu et al. (2012b) cannot compared to those in this study [8].

We used the soil and plant samples in the wetland of Jiaozhou Bay to test the prediction models. Correspondence between measured and predicted $\mathrm{C}$ fractions was examined (Fig. 4). The 
correspondence for $\mathrm{C}$ fractions is not ideal. The $\mathrm{r}^{2}$ of these models is higher than 0.75 , but still $25 \%$ of variation cannot be explained. In the past studies, chemiluminescence was used to measure the concentrations of $\mathrm{N}$ amides [17, 21-22]; therefore, $\mathrm{N}$ concentrations could influence the luminescence characteristics. Moreover, more details of chemiluminescence characteristics for different $\mathrm{C}$ fractions are needed to be studied. Further study should quantify the influence factors to improve the model accuracy and set up the prediction models in a specific spectral band.

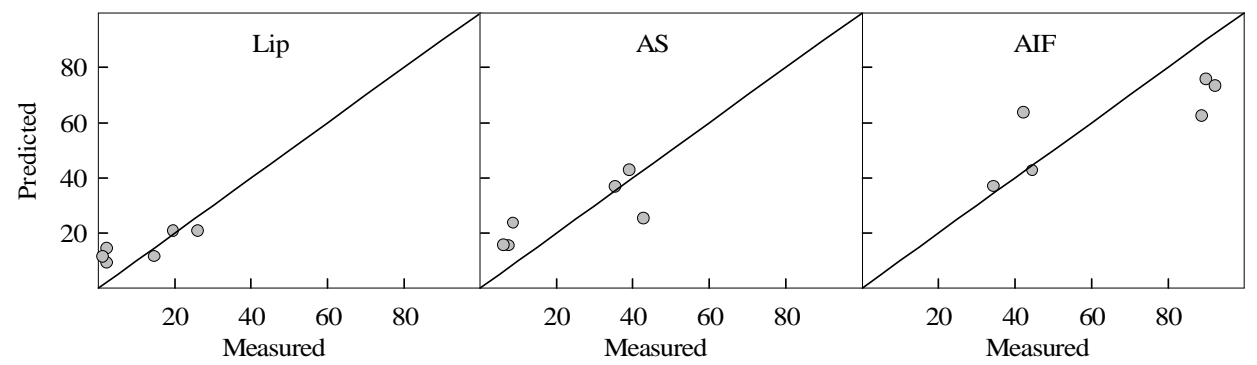

Fig. 4. Correspondence between measured and predicted $\mathrm{C}$ fractions. The lines in the figures are the $1: 1$ line.

\section{Conclusions}

We explored the use of ozonation chemiluminescence to rapidly determine $\mathrm{C}$ fractions of soil and plant materials. We studied the ozonation mechanism and set up models to predict $\mathrm{C}$ fractions by luminescence characteristics and found that 1) ozonation process is short, during which the oxygen atoms of $\mathrm{O} 3$ are integrated to the structure of new carboxyl, carbonyl, and O-Alkyl, but where the oxygen atoms of $\mathrm{O} 3$ was added is not clear; 2) Lip concentrations are predicted by the index of the power function for luminescence intensity and luminescence time ( $L i p \%=-2.94-9370.8 \times(b-V) / m$ ); 3) AS concentrations and AIF concentrations are predicted by the luminescence time $(A S \%=5.03+18.9 \times t / m, A \mathrm{I} F \%=95.85-29.5 \times t / m)$. Although some uncertainty exists in the models, this methodology provides a significant step forward from the traditional approach in labs. Further study should pay more attention to the luminescence characteristics of different $\mathrm{C}$ fractions in a specific spectral band and the influences of $\mathrm{N}$ on the prediction models.

\section{Acknowledgments}

This work was supported by the Projects of Science and Technology Development Program in Shandong Province (No. 2015GNC110016) and Shandong Provincial Natural Science Foundation, China (No. ZR2014DM012).

\section{References}

[1] F.S. Chapin III, P.A. Matson, H.A. Mooney, Principles of Terrestrial Ecosystem Ecology, Springer-Verlag, New York, 2002.

[2] D.L. Moorhead, R.L. Sinsabaugh, A theoretical model of litter decay and microbial interaction, Ecol. Monogr. 76 (2006) 151-174.

[3] P. Fan, D. Guo, Slow decomposition of lower order roots: a key mechanism of root C and nutrient retention in the soil, Oecologia 163 (2010) 509-515.

[4] I. Kögel-Knabner, The macromolecular organic composition of plant and microbial residues as inputs to soil organic matter, Soil Biol. Bioch. 34 (2002) 139-162. 
[5] P. Vávrová, B. Stenberg, M. Karsisto, V. Kitunen, T. Tapanila, R. Laiho, Near infrared reflectance spectroscopy for characterization of plant litter quality: Towards a simpler way of predicting carbon turnover in peatlands? In: J. Vymazal (ed.), Wastewater Treatment, Plant Dynamics and Mangement in Constructed and Natural Wetlands, Springer, 2008, pp. 65-87.

[6] R.R.E. Artz, S.J. Chapman, A.H.J. Robertson, J.M. Potts, F. Laggoun-Défarge, S. Gogo, L. Comont, J.-R. Disnar, A.-J. Francez, FTIR spectroscopy can be used as a screening tool for organic matter quality in regenerating cutover peatlands., Soil Biol. Bioch. 40 (2008) 515-527.

[7] M. Liu, P. Fan, Y. Liu, L. Du, Heterogeneity influence of organic matter on the ozonation chemiluminescence for soils and sediments, Advanc. Mater. Rese. 468-471 (2012a) 1850-1855.

[8] Y. Liu, P. Fan, G. Hou, J. Sun, Y. Cheng, R. Ma, Rapid determination of organic matter fractions by ozonation chemiluminescence, Advanc. Mater. Rese. 468-471 (2012b) 2842-2848.

[9] J. Lin, Theory and Application for chemiluminescence, Chemical Industry Press, Beijing, China, 2004 (in Chinese).

[10] R.G. Bulgakov, A.S. Musavirova, A.S. Abdrakhmanov, A.M. Abdrakhmanov, E.Y.

Nevyadovskii, S.L. Khursan, S.D. Razumovskii, J. Appl. Spectr. 69 (2002) 220-225.

[11] T. Takayanagi, P.K. Dasgupta, Talanta 66 (2005) 823-830.

[12] L.V. Tkhi, V.V. Tarasov, Yu.I. Popov, Theor. Found. Chem. Eng. 43 (2009) 846-849.

[13] Y. Su, H. Chen, Z. Wang, Y. Lv, Recent advances in chemiluminescence, Appl. Spectrosc. Rev. 42 (2007) 139-176.

[14] C.M. Hindson, P.S. Francis, G.R. Hanson, J.L. Adcock, N.W. Barnett, Mechanism of permanganate chemiluminescence, Analyt. Chem. 82 (2010) 4174-4180.

[15] Hamzah A, Abdullah MP, Sarmani S, Johari MA. Chemical and bacteriological monitoring of drinking water from an urbanized water catchment drainage basin, Envir. Monit. Assessm. 44 (1997) 327-338.

[16] J.Y. Hu, Z.S. Wang, W.J. Ng, S.L. Ong, Disinfection by-products in water produced by ozonation and chlorination, Envir Monit Assessm 59 (1999) 81-93.

[17] E.A. Badr, E.P. Achterberg, A.D. Tappin, S.J. Hill, C. Braungardt, Determination of dissolved organic nitrogen in natural waters using high-temperature catalytic oxidation, Trends Analyt. Chem. 22 (2003) 819-827.

[18] J.C. Lou, C.E. Huang, J.Y. Han, Y.J. Huang, Generation of disinfection by-products (DBPs) at two advanced water treatment plants, Envir. Monit. Assessm. 162 (2010) 365-375.

[19] G. Hou, Y. Liu, L. Du, G. Zhang, Rapid analysis of the organic matter in sediment and soil with the ozone oxidation chemiluminescence method, Act. Pedol. Sinic. 45 (2008) 1135-1141 (In Chinese).

[20] P.N. Nelson, J.A. Baldock, Estimating the molecular composition of a diverse range of natural organic materials from solid-state 13C NMR and elemental analyses, Biogeochemistry 72 (2005)1-34.

[21] C. Molins-Legua, S. Meseguer-Lloret, Y. Moliner-Martinez, P. Campíns-Falcó, A guide for selecting the most appropriate method for ammonium determination in water analysis, Trends Anal. Chem. 25 (2006) 282-290.

[22] M.D. Patey, M.J.A. Rijkenberg, P.J. Statham, M.C. Stinchcombe, E.P. Achterberg, M. Mowlem, Determination of nitrate and phosphate in seawater at nanomolar concentrations, Trends Anal. Chem. 27 (2008) 169-182. 